\title{
Statyba
}

\section{REINFORCEMENT INFLUENCE ON NON- AUTOCLAVE FOAM CEMENT CONCRETE STRENGTH CHARACTERISTICS}

\author{
M. Sinica , A. Dudik , A. Laukaitis \& G. Sezeman
}

To cite this article: M. Sinica , A. Dudik , A. Laukaitis \& G. Sezeman (2000) REINFORCEMENT INFLUENCE ON NON-AUTOCLAVE FOAM CEMENT CONCRETE STRENGTH

CHARACTERISTICS, Statyba, 6:3, 169-174, DOI: 10.1080/13921525.2000.10531583

To link to this article: https://doi.org/10.1080/13921525.2000.10531583

Published online: 26 Jul 2012.

Submit your article to this journal \ulcorner

Щ Article views: 73 


\title{
ARMAVIMO ITAKA PUTU CEMENTBETONIO STIPRUMO CHARAKTERISTIKOMS
}

\author{
M. Sinica, A. Dudik, A. Laukaitis, G. Sezeman \\ Termoizoliacijos institutas
}

\section{1. lvadas}

Gaminių fizikines, mechanines savybes geriausiai nusako medžiagos tankis bei makrostruktūra [1]. Akivaizdu. kad kuo tankis didesnis, tuo gaminių stiprumo charakteristikos yra geresnès. Tačiau kartais reikia medžiagų, turinčių tam tikrų savybiu, pvz., didesni stipri lenkiant. smūgini stipri. Siekiant pagerinti šias savybes, medžiagos yra armuojamos. Tam yra naudojami ivairūs pluoštiniai priedai. Betono tūriniam armavimui naudojami mineraliniai ir organiniai pluoštai [2], metaliniai segmentai [3], metalinis tinklas [4, 5]. Gipso gaminiai, be tūrinio armavimo, iš paviršiaus yra armuojami iš abieju pusių lakštinèmis medžiagomis - kartonu [6]. Tūrinis armavimas pluoštiniais priedais labiausiai paplitęs gaminant mažo tankio iki $300 \mathrm{~kg} / \mathrm{m}^{3}$ termoizoliacinius gaminius [7] arba plonasienius apdailos elementus. Tai firmu „Cetris“, „Bison“, „Eternit“ lakštai. Jiems armuoti naudojamas celiuliozès pluoštas. Tūrinis armavimas buvo nagrinètas $400-450 \mathrm{~kg} / \mathrm{m}^{3}$ tankio autoklaviniam akytajam betonui, naudojant anglies pluoštą [8] ir $700 \mathrm{~kg} / \mathrm{m}^{3}$ tankio neautoklaviniam akytajam betonui [2], naudojant mineralinius ir sintetinius pluoštus.

Šio darbo tikslas - ištirti šutinto ir kietèjusio natūraliomis salygomis puty cementbetonio stiprumo charakteristikas armuojant ji anglies pluoštu ir stiklo tinkleliu.

\section{2. Žaliavos ir tyrimų metodikos}

Kaip rišamoji medžiaga naudotas $A B$,Akmenés cementas“ CEM 42,5R markès portlandcementis, atitinkantis standarto LST 1455:1996 reikalavimus. Jo rišimosi pradžia - $60 \mathrm{~min}$, pabaiga - $600 \mathrm{~min}$. mineralinè klinkerio sudetis, \%: $\mathrm{C}_{3} \mathrm{~S}-63,63 ; \mathrm{C}_{2} \mathrm{~S}-10.55 ; \mathrm{C}_{3} \mathrm{~A}-6.47$; $\mathrm{C}_{4} \mathrm{AF}$ - 12,22. Tūriniam armavimui naudotas sintetinis anglies pluoštas. Plaušelių ilgis - iki $5 \mathrm{~mm}$, skersmuo 4,6-7,7 $\mu \mathrm{m}$. Žaliavų cheminè sudètis pateikta lentelèje.

Paviršiniam armavimui naudotas šarmams atsparus stiklo audinio tinklelis, atitinkantis austru standarto SSA - 5433-S reikalavimus. Jo akučiu dydis $4.5 \times 4,5 \mathrm{~mm}$ arba $9 \times 9 \mathrm{~mm}$. Kaip putokšlis naudotas sulfonolas, atitinkantis TS 6-01-1001-75 reikalavimus. Jo tirpalo koncentracija - $2 \%$. Putu stabilizatorius $-0,3 \%$ koncentracijos kaulų kliju tirpalas. Sulfonolo ir kaulų kliju santykis - 1:0,2. Putos 15 min plaktos laboratoriniame periodinio veikimo putų plaktuve. Formavimo mišinio $\mathrm{V} / \mathrm{K}$ yra 0,55 .

Pluoštinè medžiaga - sintetinis anglies pluoštas - buvo maišoma su vandeniu. I maišyklę buvo pridedamas reikiamas portlandcemenčio kiekis. Komponentai maišyti $1 \mathrm{~min}$, vèliau pridèta putų ir mišinys maišytas $5 \mathrm{~min}$. Formavimo mišiniais buvo užpildytos $100 \times 100 \times 100 \mathrm{~mm}$, $40 \times 40 \times 160 \mathrm{~mm}$ ir $500 \times 500 \times \mathrm{h} \mathrm{mm}$ matmenu formos, kurių aukštis (h) buvo $8,10,12,14 \mathrm{~mm}$. Vienas stiklo audinio tinklelis buvo dètas ant formu dugno prieš užpildant jas formavimo mišiniu, kitas ispaustas i formavimo masę iš viršaus ir privoluotas. Bandiniai kietejo natūraliomis salygomis 28 paras. Armuoti stiklo audinio tinkleliu bandiniai šutinti 85,65 ir $45^{\circ} \mathrm{C}$ temperatūroje. Iš paruošu $500 \times 500 \times(8-14) \mathrm{mm}$ išpjauti bandiniai $(70 \pm 2 \times 15 \pm 2 \times(8-$ 14) $\mathrm{mm}$ smūginiam stipriui nustatyti ir $40 \times 10 \times 160$, $100 \times 10 \times 220,100 \times 10 \times 450 \mathrm{~mm}$ stipriui lenkiant ivertinti.

Žaliavų cheminè sudètis

Raw Material Chemical Composition

\begin{tabular}{|l|c|c|c|c|c|c|c|c|}
\hline \multicolumn{1}{|c|}{ Žaliava } & \multicolumn{7}{c|}{ Sudetis. \% } & \multirow{2}{*}{ Kaitmenys. } \\
\cline { 1 - 7 } & $\mathrm{SiO}_{2}$ & $\mathrm{Al}_{2} \mathrm{O}_{3}$ & $\mathrm{Fe}_{2} \mathrm{O}_{3}$ & $\mathrm{CaO}$ & $\mathrm{MgO}$ & $\mathrm{SO}_{3}$ & $\mathrm{R}_{2} \mathrm{O}$ & $\%$ \\
\hline Klinkeris & 20.42 & 5,01 & 4,02 & 64.49 & 3.86 & 0.72 & 0,76 & 0.32 \\
\hline Anglies pluoštas & 3.64 & 0.13 & 0.08 & 0.26 & 0.09 & & & 95.80 \\
\hline
\end{tabular}


Bandinių tankis, stipris gniuždant ir lenkiant nustatyti standartiniais metodais. Faktinis stipris gniuždant perskaiciuotas i norimo tankio betono stipri pagal [9] metodika.

Putu cementbetonio smūginis stipris nustatytas pagal GOST $8747-88$ p. 8 reikalavimus naudojant Vilniaus universitete esantị vokišką švytuoklinị plaktą ( 1 pav.).

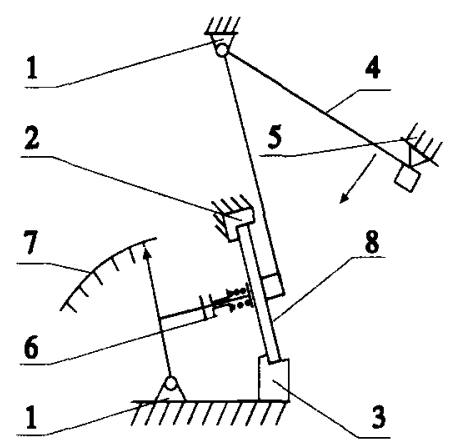

1 pav. Bandinio smūginio stiprio nustatymo schema: 1 stovas; 2,3 - atramos; 4 - švytuoklè: 5 - ribotuvas: 6 smūgio daviklis: 7 - parodymų skalè: 8 - bandinys

Fig 1. Specimen impact strength determination scheme. 1 - frame, 2,3 - supports, 4 - pendulum. 5 - restrictor, 6 measuring element, 7 - scale, 8 - specimen

Armuoto stiklo audinio tinkleliu putų cementbetonio smūginio stiprio rezultatai palyginti su plokščio asbestcemenčio lakštais (šiferiu) ir „Bison“ firmos lakštų analogiškais bandymų rezultatais. Bandiniai bandyti prieš tai juos vieną parą išlaikius vandenyje $(20 \pm 3)^{\circ} \mathrm{C}$ temperatūroje.

\section{Rezultatai ir jų aptarimas}

Siekiant išvengti mikroplyšių, atsiradusių kietejančiame betone, ji armuojame sintetiniu anglies pluoštu. Nedideli armuojančiųjų medžiagu kiekiai $(0,2-0,4 \%$ nuo kietuju medžiagu masès) padidina $900 \mathrm{~kg} / \mathrm{m}^{3}$ tankio putų cementbetonio stiprị lenkiant nuo $6 \mathrm{iki} 24,5 \%$ (2 pav. a).

Armuotu sintetiniu anglies pluoštu putu cementbetonio bandinių stipris gniuždant mažai kuo skiriasi nuo kontrolinio ( 2 pav. b) ir jų kreivès sutampa.

Tirdami skelto bandinio makrostruktūra, pastebime styrančius anglies pluošto plaušelius (3 pav.). kurie veikiant apkrovai nenutrūksta ir nelūžta, bet išsitraukia iš putų cementbetonio. Todèl galime padaryti išvadą, kad armuojančiosios medžiagos pluošto stiprumas yra didesnis už sukibimo jègą tarp pluošto ir putų cementbetonio.
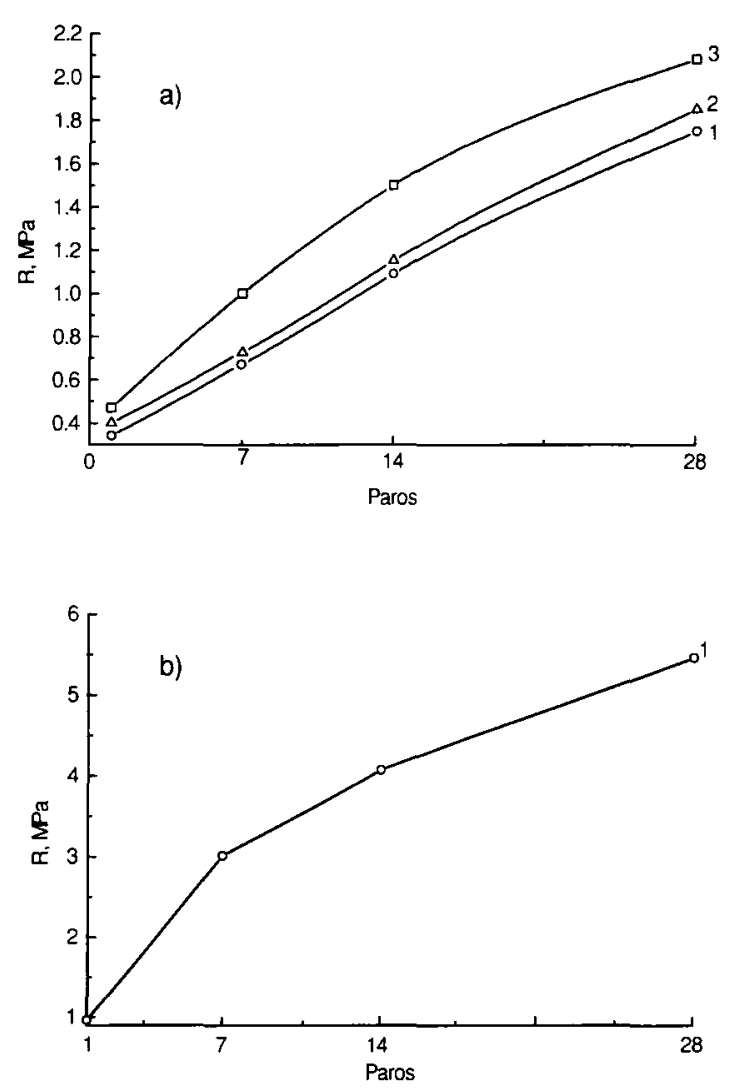

2 pav. Pluoštu armuoto putu cementbetonio stiprumo charakteristiku kinetika: stipris lenkiant (a) ir stipris gniuždant (b). Armuojančiųiu priedų kiekis. \%: I - 0: $2-0,2 ; 3$ $-0,4$

Fig 2. Reinforced with fibres foam cement concrete strength characteristic kinetics: flexural strength (a) and compression strength (b). Amount of reinforcing additives, $\%: 1-0: 2-0,2: 3-0,4$

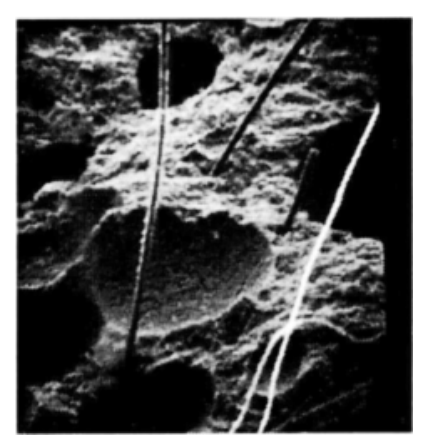

3 pav. Pluoštu armuoto putụ cementbetonio makrostruktūra $(\times 60)$

Fig 3. The macrostructure of foam cement concrete reinforced with fibres $(\times 60)$ 
Bandinių, armuotu $0,2 \%$ sintetiniu anglies pluoštu, paviršius buvo padengtas stiklo audinio tinkleliu, panardinant ji i formavimo masę iki $2 \mathrm{~mm}$. Tinklelio akučiu dydis buvo $4,5 \times 4.5$ ir $9 \times 9 \mathrm{~mm}$. Bandiniai, armuoti $4,5 \times 4,5 \mathrm{~mm}$ tinkleliu, yra dvigubai stipresni lenkiant negu kontroliniai, o armuoti $9 \times 9 \mathrm{~mm}$ tinkleliu -1.8 karto (4 pav.)

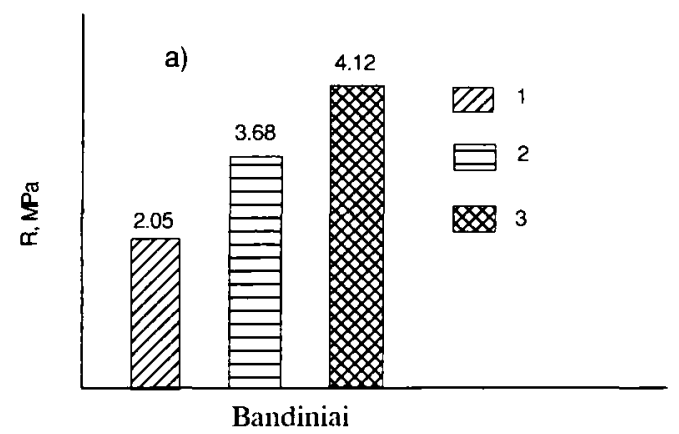

4 pav. Armavimo tinklelio itaka putų cementbetonio. pagaminto su $0,2 \%$ anglies pluoštu, stipriui lenkiant: 1 kontrolinis (be tinklelio), 2 - tinklelis su akutemis $9 \times 9 \mathrm{~mm}, 3$ - tinklelis su akutėmis $4.5 \times 4,5 \mathrm{~mm}$

Fig 4. Reinforcing net influence on foam cement concrete made with $0,2 \%$ carbon fibre flexural strength: 1 - control (without net), 2 - net with $9 \times 9 \mathrm{~mm}$ mesh. 3 - net with $4.5 \times 4,5 \mathrm{~mm}$ mesh

Tolesniems bandymams buvo pasirinktas stiklo audinio tinklelis, kurio akucių dydis yra $4,5 \times 4,5 \mathrm{~mm}$. Buvo tirta armuoto puty cementbetonio bandinių stiprio lenkiant priklausomybè nuo medžiagos storio ir bandinių matmenų. Standartiniai bandiniai - prizmès, kurių storis $40 \mathrm{~mm}$. suirdavo (5 pav. 1 ir 2 bandiniai). Plonasieniai bandiniai (storis $-10 \mathrm{~mm}$ ) iš pradžių išlinkdavo ir tik vèliau suirdavo, tačiau tinklelis nesuirdavo. Palyginimui buvo išbandytas gipso kartono lakštas. Bandymo metu jis vidutiniškai išlinko $10,5 \mathrm{~mm}$, o putų cementbetonio bandiniai - nuo 5 iki $25 \mathrm{~mm}$. Tai susiję su bandinių ilgiu, kuris bandymy metu buvo 160;220 ir $450 \mathrm{~mm}$. Armuotu stiklo audiniu plonasienių puty cementbetonio bandinių stipris lenkiant siekė 5,12-6,55 MPa, kas yra beveik $8 \%$ daugiau už standartinę armuotą prizmę ( 5 pav. 2 ir 3 bandiniai), ir du kartus daugiau už putų cementbetoni be tinklelio ( 5 pav. 3 ir 1 bandiniai). Didinant bandinių ilgi iki 220 ir $450 \mathrm{~mm}$ stipris lenkiant mažai kuo skyrési ( 5 pav. 4 ir 5 bandiniai). Plonasieniai $10 \mathrm{~mm}$ storio bandiniai veikiant apkrovai išlinkdavo, o nuèmus ją sugriždavo i pradinę padètị. Lakštai spyruokliuodavo, bet nesuirdavo.

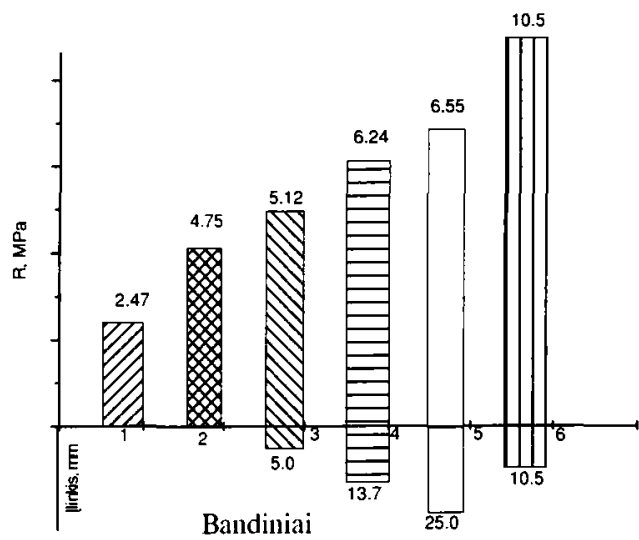

5 pav. Putu cementbetonio stiprio lenkiant ir ilinkio priklausomybe nuo medžiagos storio ir bandiniụ sudeties bei matmenų. Bandiniu matmenys. mm: $1-40 \times 40 \times 160$ be tinklelio: $2-40 \times 40 \times 160$ armuoti tinkleliu; 3 $40 \times 10 \times 160$ armuoti tinkleliu, $4-100 \times 10 \times 220$ armuoti tinkleliu, $5-100 \times 10 \times 450$ armuoti tinkleliu, 6 $100 \times 10 \times 450$ gipso kartonio lakštas - palyginamasis

Fig 5. Foam cement concrete flexural strength and concavity dependency on material thickness, sample composition and dimensions. Sample dimensions, mm: 1 $40 \times 40 \times 160$, without net: $2-40 \times 40 \times 160$ reinforced with net; $3-40 \times 40 \times 100$ reinforced; $4-100 \times 10 \times 220$ reinfor-

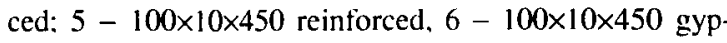
sum board (for comparison)

Armuoto putų cementbetonio bandinių smūginis stipris beveik nepriklauso nuo storio ir siekia $(7,0-8,0) \cdot 10^{-3}$ $\mathrm{MPa} \cdot \mathrm{m}$ (6 pav. 1-4 bandiniai). Tuo tarpu bandinio be tinklelio smūginis stipris - tik $1,35 \cdot 10^{-3} \mathrm{MPa} \cdot \mathrm{m}, \mathrm{t}$. y. daug mažesnis už kontroliniu gaminių ( 6 pav. $5,6,7$ bandiniai).

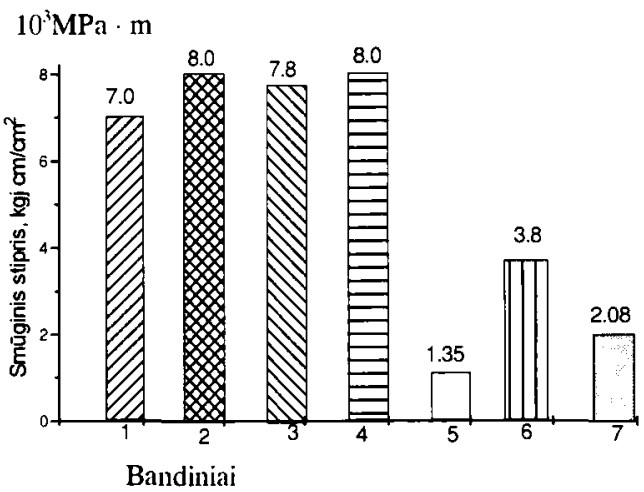

6 pav. Putu cementbetonio smũginio stiprio priklausomybẻ nuo medžiagos storio ir armavimo būdo. Iš abieju pusiụ tinkleliu armuotụ bandinių storis, mm: 1 - 14: 2 12: 3 - 10: 4 - 8. 5 - be tinkleliu. storis $10 \mathrm{~mm} ; 6$ ir 7 kontroliniai, $10 \mathrm{~mm}$ storio plokšti asbestcementinis ir „Bison" firmos lakštai

Fig 6. Foam cement concrete impact strength dependency on material thickness and reinforcement. Samples reinforced by net on both sides at thicknesses, mm: 1 - 14: 2 12: 3 - 10: $4-8: 5$ - without net. thickness $10 \mathrm{~mm}, 6$ and 7 -control, $10 \mathrm{~mm}$ thickness asbestoscement and „Bison” firm sheets 
Taip armuoti putų cementbetonio gaminiai pasižymi dideliu atsparumu smūgiams.

Toliau buvo tirta šutinimo itaka tinkleliu armuoto putu cementbetonio stiprumo charakteristikoms. Žinoma, kad šutinimas padidina puty cementbetonio stiprumą lenkiant [10], o gaminiu šutinimo trukmé priklauso nuo jo temperatūros [11]. Kadangi panaudotas stiklo audinio tinklelis yra padengtas polimerine danga. šarminèje terpèje esant aukštesnei temperatūrai jis gali prarasti savo stiprumo charakteristikas.

Gauti rezultatai leidžia teigti, kad esant 65 ir $85^{\circ} \mathrm{C}$ temperatūrai, bandinių stipris lenkiant nedideja ir siekia 1,2-1.3 MPa, esant stipriui gniuždant 2,8-3 MPa (7 pav. a ir b). Matyt, esant šioms šutinimo temperatūroms, vyksta stiklo audinio paviršiuje esančio polimerinio sluoksnio dalinis ardymas.

Remiantis gautais rezultatais, bandinių šutinimo temperatūru intervalas buvo siaurinamas $\left(45-60^{\circ} \mathrm{C}\right)$, keičiant ji kas $5^{\circ} \mathrm{C}$. Nustatyta, kad, šutinant putu cementbetonio bandinius $45-55^{\circ} \mathrm{C}$ temperatūrose, stiklo audinio tinklelio apsauginis polimerinis sluoksnis dar neardomas, ir bandinių stipris lenkiant apie 2,6 karto didesnis negu bandinių, šutintụ $55-85^{\circ} \mathrm{C}$ temperatūrose.

a)

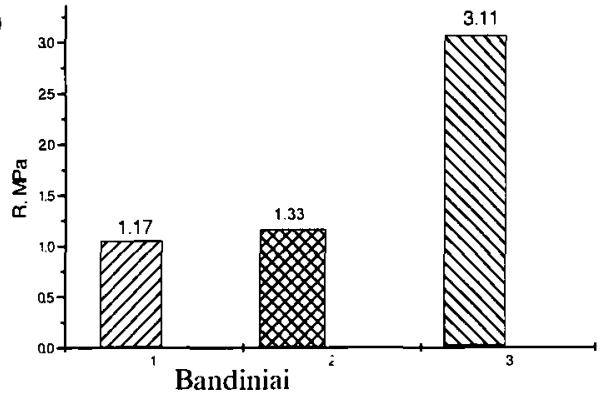

b)

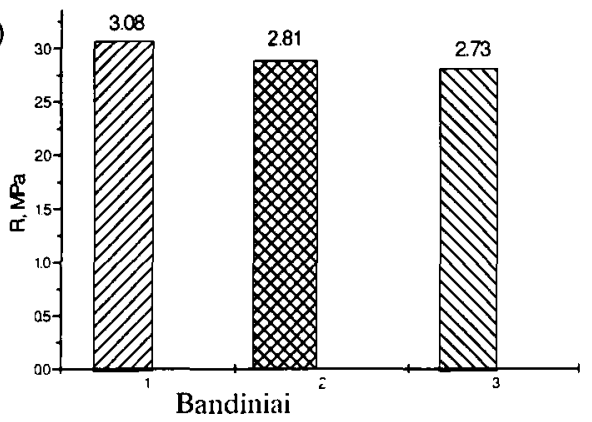

7 pav. Śutinimo jtaka tinkleliu armuoto putu cementbetonio stipriui lenkiant (a) ir stipriui gniuždant (b). Šutinimo režimas $2+20+2$ h. Šutinimo temperatūra ${ }^{\circ} \mathrm{C}: 1-85,2-$ $65.3-45$

Fig 7. Net-reinforced foam cement concrete steaming temperature influence on material flexural strength (a) and compression strength (b). Steaming regime $2+20+2 \mathrm{~h}$. Steaming temperature. ${ }^{\circ} \mathrm{C}: 1-85,2-65.3-45$
Šutintų ir kietejusių natūraliomis salygomis putų cementbetonio bandinių mikrostruktūra nepakito. Tai patvirtino bandinių rentgenofazinè ir termografiné ( 8 ir 9 pav.) analizès.

Kaip matyti iš rentgenogramų ( 8 pav.), bandinių mikrostruktūros pagrindą sudaro hidratuoti cemento mineralai $\mathrm{C}_{3} \mathrm{~S}, \mathrm{C}_{2} \mathrm{~S}, \mathrm{C}_{3} \mathrm{~A}, \mathrm{C}_{4} \mathrm{AF}$. Vykstant cemento mineralu hidratacijai, susidaro apie $6 \%$ laisvojo $\mathrm{Ca}(\mathrm{OH})_{2}$. kuri rentgenogramose identifikuoja ryškios linijos 1,$45 ; 1,49$; 1,$69 ; 1.79 ; 1,97 ; 2,63 ; 3,11 \AA$ ( 8 pav.), taip pat termogramose ( 9 pav.) endoterminis efektas esant $540-560^{\circ} \mathrm{C}$. rodantis $\mathrm{Ca}(\mathrm{OH})_{2}$ dehidratacija. Termogramose taip pat galima pastebéti endoterminius efektus 140 ir $200{ }^{\circ} \mathrm{C}$ temperatūrose. charakteringus vandens išsiskyrimus
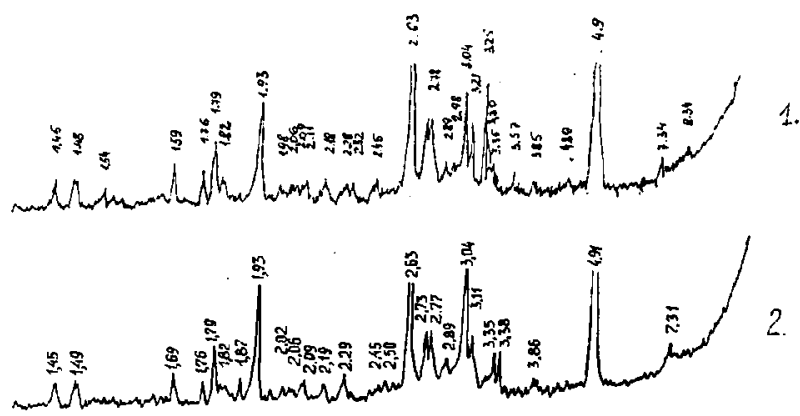

8 pav. Putų cementbetonio bandinių rentgenogramos: 1 kietẹjusių natūraliomis sąlygomis: 2 - šutintų

Fig 8. Foam cement concrete X-raygrams: 1 - hardened in natural conditions: 2 - steamed

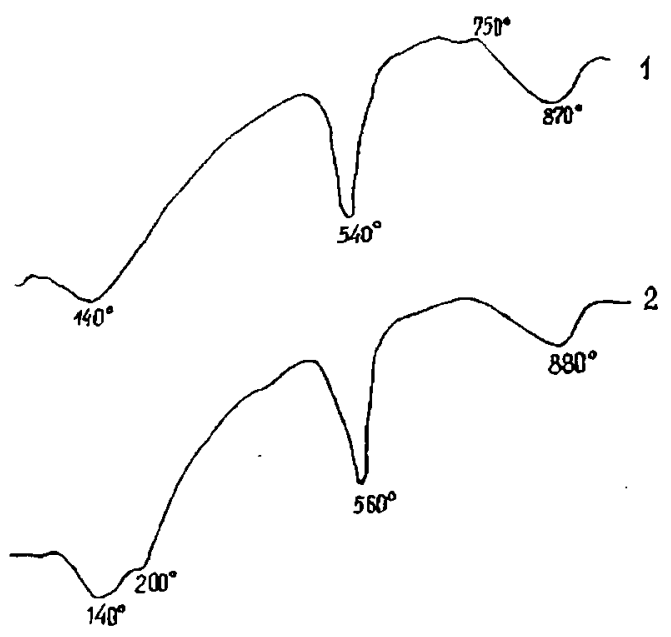

9 pav. Putụ cementbetonio bandinių termogramos: 1 kietejjusių natūraliomis sąlygomis: 2 - šutintų

Fig 9. Foam cement concrete thermograms: 1 - hardened in natural conditions: 2 - steamed 
tobermorito grupés hidrosilikatams. Vyrauja CSH (I) grupès kalcio hidrosilikatai, identifikuojami linijomis 1,$82 ; 2.78 ; 3,04 ; 7,31 \AA ̊$ (8 pav.). Kietèjusių natūraliomis sąlygomis ir šutintų putu cementbetonio bandinių fazinè naujadarų sudètis mažai skiriasi.

\section{Išvados}

1. Paviršinis šutinto arba kietėjusio natūraliomis sąlygomis putu cementbetonio armavimas stiklo audinio tinkleliu priklausomai nuo tinklelio akučių dydžio padidina stiprị lenkiant 1,8-2,0 kartus, o smūginị stiprị 5,5 karto.

2. Iš abiejų pusių armuoti stiklo audiniu plonasieniai putu cementbetonio gaminiai yra elastingi - apkrovus išlinksta iki $25,0 \mathrm{~mm}$, o apkrovą nuèmus sugrižta i pradinę būklę.

3. Nustatyta, kad, šutinant armuotus stiklo audinio tinkleliu putu cementbetonio gaminius $45-55^{\circ} \mathrm{C}$ temperatūroje, tinklelio apsauginis polimerinis sluoksnis nesuardomas.

4. Šutinti ir kietejję natūraliomis salygomis putụ cementbetonio bandiniai turi vienodą medžiagos mikrostruktūrą, kurią sudaro CSH (I) grupès kalcio hidrosilikatai, hidratuoti portlandcemenčio klinkerio mineralai ir $\mathrm{Ca}(\mathrm{OH})_{2}$.

\section{Literatūra}

1. А.Г. Комар. Строительные материалы и изделия. Москва: Высшая школа. 1976. 535 с.

2. A. Laukaitis, A. Dudik, J. Kerienè. Pluoštinių priedų jtaka puty cementbetonio mikrostruktūrai ir fizikinèms mechaninems savybems // Cheminè technologija. Nr. 3. Kaunas: Technologija, 1999, p. 87-92.

3. "Harex" firmos (Vokietija) $1994 \mathrm{~m}$. reklaminis prospektas. 3 p.

4. Е. С. Силаенков. Долговечность изделий из ячеистых бетонов. Москва: Стройиздат. 1986.176 с.

5. R. Ragaǐ̌sis. Sintetinis pluoštas antriniam betono armavimui // Mokslas ir technika. Nr.9. Vilnius: Spauda, 1996. p. 12-13.

6. GOST 6266-89. Gipso kartono lakštai. 15 p.

7. A. Laukaitis. Technologinių veiksnių itaka akytojo betono formavimo mišinių ir produkto savybèms. Habilitacinis darbas. Kaunas, 1999. 101 p.

8. A. Laukaitis. Influence of Carbon Fiber Additive on Porous Silicate Concrete Formation Mixtures and Product Properties // Medžiagotyra. Nr. 2(5). Kaunas: Technologija, 1997, p. 42-45.

9. A. Laukaitis. Akỵtojo betono sudečiu skaičiavimas ir jo savybių týrimo metodikos / Termoizoliacija. Vilnius. 1996. 24 p.
10. M. Sinica, A. Dudik, A. Laukaitis. Šutinimo itaka 600$1000 \mathrm{~kg} / \mathrm{m}^{3}$ tankio puty cementbetonio deformacijoms // Cheminè technologija. Nr. 1. Kaunas: Technologija, 2000, p. 5-9.

11. С. А. Миронов. Рост прочности бетона при пропаривании и последуюшем твердении. Москва: Стройиздат. $1973.95 \mathrm{c}$.

Iteikta 19991206

\section{REINFORCEMENT INFLUENCE ON NON- AUTOCLAVE FOAM CEMENT CONCRETE STRENG'TH CHARACTERISTICS}

\section{Sinica, A. Dudik, A. Laukaitis, G. Sezeman}

Sum mary

The volume and surface reinforcement treatment influence on $900-1000 \mathrm{~kg} / \mathrm{m}^{3}$ density non-autoclave foam cement concrete strength characteristics are discussed in this paper.

Carbon fibres of a length up to $5 \mathrm{~mm}$ and diameter of 4,6 $7.7 \mathrm{mkm}$ were used for volume reinforcement. An alkaliresistant glass fabric net with a 4,5 or $9 \mathrm{~mm}$ mesh satisfying the requirements of Austrian standard SSA-5433 was used for surface reinforcement. The chemical composition of raw materials used are given in Table 1 . One glass fabric net was put on the form bottom before pouring the mixture, while the other net was put on top, pushed into the formation mixture and trowelled with a roller.

The material contracts when the Portland cement hardens and microcracks appear. These microcracks have a negative influence on the materials structure, it decreases the materials strength characteristics, frost-resistance and durability. Small amounts of synthetic carbon fibres $(0.2-0.4 \%$ based on solids) increase the $900 \mathrm{~kg} / \mathrm{m}^{3}$ density foam cement concrete flexural strength from 6 to $24.5 \%$ (Fig 2).

The carbon fibre adhesion to foam cement concrete is insufficient. The fibres are dragged out of the material during bending or extension (Fig 3). Besides volume reinforcement, surface reinforcement was tested by introducing a glass fabric net $2 \mathrm{~mm}$ below the formation mixtures surface. All the specimens were additionally reinforced with $0,2 \%$ carbon fibre. The obtained results show that samples reinforced with a 4.5 mesh net have a twice better flexural resistance than control samples. Samples reinforced with a $9 \mathrm{~mm}$ mesh glass fabric net showed a 1.8 time increase (Fig 4). The dependency of reinforced foam cement concrete flexural strength on material thickness and samples size were also investigated. Compressive strength measurement experiments showed that standard prisms $(40 \times 40 \times 160 \mathrm{~mm})$ ruptured regardless whether they were reinforced with carbon fibres or additionally by a glass fabric net (Fig 5, samples 1, 2). Thin-wall specimens under load bent at first, later ruptured. however the net was not destroyed. A gypsum board was also tested for comparison. The obtained data is given in Fig 5. Thin-wall $(10 \mathrm{~mm})$ specimens under al load bent and returned to initial position when the load was removed during testing. The boards behaved springly, but did not rupture.

It was found that thin-wall foam cement shock-resistance does not depend on the article thickness. It was compared with "Bison" firm boards. The obtained results are given in Fig 6. As we can see, reinforced foam cement concrete specimen shockresistance reaches a $(7,0 \div 8,0) \cdot 10^{-3} \mathrm{MPa} \cdot \mathrm{m}$ value, while specimens without a reinforcing net give a shock-resistance value of only $1,35 \cdot 10^{-3} \mathrm{MPa} \cdot \mathrm{m}$, which is substantially lower than for control samples. It is well known, that steaming increases the cement concrete flexural strength $|10|$ and the 
steaming duration depends on its temperature [11]. It was determined, that with the aim of ensuring the glass fibre surface polymer layer stability, the steaming should be conducted at 45$50{ }^{\circ} \mathrm{C}$ temperature. In this case, its flexural strength increases by 2,6 times (Fig 7a, sample 3) in comparison with the interval of temperatures $55-85^{\circ} \mathrm{C}$.

The steamed and hardened in natural conditions foam cement concrete microstructure is similar. This was confirmed by $\mathrm{X}$-raygrams and thermograms (Fig 8 and 9). So we came to the conclusion. that clinker mineral hydratation takes place during the hardening of foam cement concrete and tobermorite groups calcium hydrosilicates are formed.

The main conclusion: we can increase the flexural strength up to 2 times and the shock-resistance by 5.5 times by reinforcing non-autoclave foam cement concrete with a glass fibre.

Marijonas SINICA. Laboratory Head, Institute of Thermal Insulation. Linkmenų g. 28. LT-2600 Vilnius, Lithuania.

A graduate of Vilnius Civil Engineering Institute (1972). Author or co-author of 25 papers, 39 inventions and 1 patent. Research of interests: porous concrete thermal insulation materials and articles, its production technology and eguipment.
Antanas LAUKAITIS. Dr Habil (technological sciences). Director of Institute Thermal Insulation. Linkmenų g. 28. LT-2600 Vilnius, Lithuania.

A graduate of Kaunas Polytechnic Institute (industrial engineer, 1967). Doctor (1975). Dr Habil (1999). Author of 87 papers. 16 inventions and 4 patents. Research interests: thermal insulation and acoustical products made of porous concrete and their technology, heat insulating and acoustical materials.

Aleksandr DUDIK. Research worker of Institute Thermal Insulation. Linkmenų g. 28. LT-2600 Vilnius. Lithuania.

A graduate of Belorussian Polytechnic Institute (industrial engineer. 1965). Author of 47 papers, 9 inventions. Research interests: technology of porous concrete and its products.

Georgij SEZEMAN. Research worker of Institute Thermal Insulation. Linkmenu g. 28. LT-2600 Vilnius. Lithuania

A graduate of Vilnius University (chemist, 1970). Author of 28 papers, 11 inventions. Research interests: thermal insulation from calcium hydrosilicate. 